\title{
Implementation of a program to improve the quality of colonoscopy increases the neoplasia detection rate: a prospective study
}

Authors

Institution
Luis Alberto Viola, Federico Cassella, Andrés Wonaga, Gloria Arnao Dellamea, Leandro Di Paola, Rodrigo Ubeira Salim, José Luis Fernández

Centro Integral de Gastroenterología, Buenos Aires, Argentina.

\section{Bibliography}

DOI http://dx.doi.org/

10.1055/s-0041-107800

Published online: 11.1.2016

Endoscopy International Open 2016; 04: E68-E72

(c) Georg Thieme Verlag KG

Stuttgart · New York

E-ISSN 2196-9736

\section{Corresponding author}

Luis Alberto Viola

Centro Integral de

Gastroenteologia

Buenos Aires

Argentina

violaluis@yahoo.com
Background and study aims: Endoscopists worldwide have been encouraged to report quality indicators in order to evaluate their performance. We aimed to determine whether a program to improve the quality of colonoscopy results in better rates of neoplasia detection.

Patients and methods: This is a prospective study set in a private endoscopy center. From May 2009 to March 2010, we evaluated 1573 consecutive colonoscopies (group 1). After the implementation of a quality program, from February 2011 to January 2012, we prospectively evaluated 1583 colonoscopies (group 2). Our quality-enhancing intervention consisted of instructing both patients and endoscopists. We measured the cecal intubation rate and the neoplasia detection rate. Overall neoplasias, high-risk adenomas, carcinomas, right colon adenomas, and adenomas detected in screening studies were analyzed.

\section{Introduction}

$\nabla$

As the number of colonoscopies being performed has risen, concern has increased about missed lesions, incomplete polypectomies and interval colorectal cancer (CRC). Suboptimal levels of colonoscopy quality are suspected to be partly responsible for these flaws $[1,2]$. Both the efficacy of colonoscopy and the success of screening and surveillance programs have been theorized to depend on the quality of the procedure [3-5]. Moreover, specific quality parameters have been considered independent predictors of interval cancer risk $[4,6]$. Therefore, endoscopists worldwide have been encouraged to report quality indicators and institutional improvement programs in order to evaluate their performance [5,7-9]. It has been argued that quality measurements are expensive and difficult to accomplish in a busy practice [10]. However, a study demonstrated that members of a private center can evaluate their performance and measure critical aspects
Results: Cecal intubation was documented in 1384 cases from group 1 (88\%) and 1534 from group 2 (96.9\%) $(P<0.0001)$. The neoplasia detection rates in groups 1 and 2 were, respectively: neoplasias 288 (18.3\%) and 427 (27\%) $(P<$ $0.0001)$, high-risk adenomas $76(4.8 \%)$ and 142 (9\%) $(P<0.0001)$, carcinomas $16(1 \%)$ and 21 (1.3\%) $(P=0.52)$, right colon adenomas $112(7.1 \%)$ and $154(9.7 \%)(P=0.01)$, and adenomas 141 (16.5\%) and $233(28 \%)(P<0.0001)$.

Conclusions: Implementation of a quality program improves the neoplasia detection rate. Because of the small number of cancerous lesions found in both groups, we were unable to identify differences in the carcinoma detection rate.

\section{License terms}

of their practice to improve the quality of patient care [11].

Indicators of colonoscopy quality have been investigated separately in several studies, most of them retrospective or based on academic scenarios $[6,11-16]$. Considering these antecedents, we decided to carry out a prospective study aimed at assessing whether implementation of a program to improve the quality of colonoscopy increases the neoplasia detection rate in the everyday scenario of our nonacademic private endoscopy center.

\section{Patients and methods $\nabla$}

From May 2009 to March 2010, we prospectively analyzed 1573 consecutive outpatient colonoscopies in order to evaluate our performance in terms of quality (Group 1 ). At the end of this period we implemented a quality enhancement program, focused both on patients and physicians, 
based on international guidelines for colonoscopy practice. From February 2011 to January 2012, we then prospectively analyzed 1583 consecutive colonoscopies in order to evaluate the effect of our intervention (Group 2).

Our private center is devoted to clinical gastroenterology and endoscopy practice. Virtually all patients attending the center belong to health private insurance systems and live in the Buenos Aires city area. Colonoscopies were performed in consecutive outpatients under routine indications of everyday clinical practice by five experienced endoscopists (LAV, AW, GAD, LDP, RUS). They used GIF-0140, GIF-0150 and GIF-0160 video endoscopes (Olympus Medical Systems Corp, Tokyo, Japan). All the procedures were performed under propofol sedation.

Written informed consent for endoscopy was obtained from all the patients. No additional procedures other than those indicated by the prescribing physicians or by the endoscopic findings were performed. We only performed a service improvement project and our institutional reviewers considered that another special consent was not required.

Patients with a previous diagnosis of inflammatory bowel disease or colonic resections were excluded from the study. In order to evaluate the homogeneity of both groups, we compared mean age, gender, and number of screening colonoscopies, including in this group high-risk (family history of CRC) and average-risk endoscopies (aged older than 50 years). Severe complications of the procedure were recorded.

\section{Quality program}

Our quality-enhancing intervention consisted of instructing both patients and physicians.

Patients were instructed to follow a diet for 3 days before the procedure that excluded fruits, vegetables, cereals, seeds, and dairy products. During the day before colonoscopy, we recommended consumption of an infusion, crackers and quince jelly for breakfast, a mid-afternoon snack, and a plate of pasta and gelatin for lunch. Clear liquids were allowed up to 4 hours before the procedure. The selected cleansing agent was monosodium phosphate/ disodium phosphate $\left(\right.$ Novonil $\left.^{\circledR}\right)$, except in patients aged 70 years and older or who had a history of kidney failure, severe hypertension or congestive heart failure. Polyethylene glycol (Barex ${ }^{\circledR}$ ) was the recommended option in these cases [17]. All bowel preparations were performed using a two-dose scheme with an interval of 2 hours between doses. Patients took the two doses the previous evening when the study was performed in the morning and early in the morning when the study was performed in the afternoon.

Endoscopists were instructed to systematically register cecal intubation, both in the written report and in the photographic documentation, and to employ a minimum of 6-minute withdrawal time from the deep cecum to the anus (measured by the use of a timer) in all studies not requiring polypectomies or biopsies. In order to evaluate colon cleansing more objectively, endoscopists were trained in the use of the Boston Bowel Preparation Scale (BBPS) with a learning video. They were also trained to look for mucus-covered lesions in the right colon. Training of endoscopists included weekly meetings devoted to analyze each item related to quality of colonoscopy by means of lectures, learning videos, and analysis of videos recorded in our center. Training also included a self-directed teaching during each endoscopy session. Reports were custom-designed so as to include the indication for colonoscopy (i.e. average-risk screening, personal history of neoplasia, family history of neoplasia or symptoms), cleansing evaluation according to the BBPS and proper documentation of the extension of the colon reached and of the lesions found.

\section{Quality indicators}

To assess the results of our program, we defined several parameters as quality indicators. First, we analyzed colon preparations using the BBPS. We considered a cutoff of 6 points to differentiate patients with adequate preparation from those with inadequate preparation, assuming that patients with scores of 8 and 9 had an excellent preparation and visualization of mucosa; patients with scores of 6 and 7, a good preparation; and patients with scores of less than 6, a fair preparation. We also used an average BBPS for the comparison of patients with and without neoplasias. Second, we analyzed patients according to the time the procedure was performed. If their colonoscopies were performed between 8 am and $10 \mathrm{am}$ or $2 \mathrm{pm}$ and $4 \mathrm{pm}$, patients were included in the "early group." If colonoscopies were performed after 10 am or $4 \mathrm{pm}$, they were included in the "late group." With this division we aimed to evaluate whether colonoscopies performed in hours closer to the last dose of laxative had a better colon cleansing and consequently better rates of neoplasia detection.

Finally, we classified our patients according to the institution where the prescribing physician was employed. Because in our unit we perform colonoscopies prescribed not only by the gastroenterologists of our own center, but also by various specialists (namely gastroenterologists, clinicians, oncologists and surgeons) from other institutions, we divided our population into "internal" patients when the colonoscopies were prescribed by our own gastroenterologists and "external" patients when they were prescribed by physicians from other institutions. Both groups received written instructions, but during consultation with internal patients, our gastroenterologists systematically explained issues regarding the preparation and the procedure. We hypothesized that bowel cleansing would improve when oral and personalized explanations were added to the usual written instructions.

We defined cecal intubation as deep intubation within the cecum, with the tip of the endoscope being able to touch the appendiceal orifice, thus allowing visualization of the inner wall [7].

\section{Outcomes}

Outcomes included the cecal intubation rate and the neoplasia detection rate correctly recorded in the report. Neoplasia detection rate was considered as the percentage of patients with at least one adenoma, taking into account the more severe lesion and independent of the number of lesions found. When the rate of neoplasia detection was evaluated, overall detection and detection of high-risk adenomas, carcinomas, right colon adenomas and adenomas in screening studies were analyzed. High-risk adenomas were defined as those either larger than $1 \mathrm{~cm}$ (measured by an open biopsy forceps), villous or tubulo-villous, serrated, or with high-grade dysplasia $[18,19]$.

\section{Data analysis}

The anonymous database was evaluated by two independent gastroenterologists who had not performed the endoscopies (FC, JLF). We used a chi-squared test for the statistical analysis of dichotomous variables. After confirming the normal distribution of our data, we used an unpaired Student's $t$ test for the continuous variables. A $P$ value lower than 0.05 was considered significant. We calculated the corresponding odds ratios (OR) with their 
respective $95 \%$ confidence intervals $(95 \% \mathrm{CI}$ ) as measures of association.

\section{Results}

\section{Basal comparison of both groups}

There were no differences between the 1573 colonoscopies in group 1 and the 1583 colonoscopies in group 2 regarding mean age, sex, and indication for colonoscopy. In group 1, the mean age of patients was $57.29 \pm 12.01$ years in group 1 and $56.83 \pm 11.64$ years in group $2(P=0.27)$. Seven hundred and twenty-eight (46.3\%) patients in group 1 and $780(49.3 \%)$ in group 2 were men $(P=0.10)$. There were 854 screening colonoscopies in group $1(54.3 \%)$ and 833 in group $2(52.6 \%)(P=0.37)$ ( $\triangle$ Table 1 ). The average dose of propofol was $300 \mathrm{mg}$ (range 200 to $600 \mathrm{mg}$ ). Three severe adverse events were observed: two bleeding episodes, one in each group, which stopped after the endoscopic treatment, and one overt perforation in group 1 that required surgical treatment.

\section{Cecal intubation}

Cecal intubation was documented in 1384 cases from group 1 (88\%) and 1534 from group $2(96.9 \%)(P<0.0001)$. The section of colon reached by the colonoscope was documented in 1481 cases from group 1 (94.2\%) and in all cases from group $2(100 \%)(P<$ 0.0001 ). Even considering the possibility that the 92 non-documented colonoscopies were complete studies, this increased rate of cecal intubation in group 1 would remain significantly lower than the rate in group $2(P<0.0001)$.

\section{Neoplasia detection}

The neoplasia detection rate was $18.3 \%$ (288 patients with neoplasias) in group 1 and $27.0 \%$ (427 patients with neoplasias) in group $2(P<0.0001)$.

High-risk adenomas were detected in 76 patients (4.8\%) from group 1 and $142(9 \%)$ from group $2(P<0.0001)$. Carcinomas were detected in 16 patients (1\%) from group 1 and $21(1.3 \%)$ from group $2(P=0.52)$.

Serrated adenomas were detected in 11 patients $(0.7 \%)$ from group 1 and in $14(0.9 \%)$ from group $2(P=0.70)$, all of them in the right colon.

Neoplasias were located in the right colon in 112 patients $(7.1 \%)$ from group 1 and in 154 patients $(9.7 \%)$ from group $2(P=0.01)$. The neoplasia detection rate was $16.5 \%$ (141 patients with neoplasias) in the 854 screening colonoscopies from group 1 and $28 \%$ (233 patients with neoplasias) in the 833 screening colonoscopies from group $2(P<0.0001)$.

Neoplasia detection rates in both groups are summarized in - Table 2.

\section{Quality indicators in group 2}

When data about bowel preparation were analyzed, the mean BBPS was $6.65 \pm 1.5$ in patients with neoplasias and $6.43 \pm 1.6$ in patients without neoplasias $(P=0.017)$. Neoplasias were detected in 333 of 1174 cases with a BBPS greater than or equal to 6 (28.4\%) and in 91 of 406 cases with a BBPS lower than $6(22.4 \%)$ $(P=0.02$, OR 1.37 [95\% CI $1.04-1.80])$. Three patients were excluded from the analysis of bowel preparation because they had rectal tumors that did not allow the passage of the endoscope.
Table 1 Basal comparison between Group 1 and Group 2.

\begin{tabular}{|c|c|c|c|}
\hline \multirow[t]{2}{*}{ Detection rate } & Group 1 & Group 2 & $P$ \\
\hline & $n=1573$ & $n=1583$ & \\
\hline $\begin{array}{l}\text { Mean age } \\
(\text { years } \pm S D)\end{array}$ & $57.29 \pm 12.01$ & $56.83+11.64$ & 0.27 \\
\hline Men [n (\%)] & $728(46.3)$ & $780(49.3)$ & 0.10 \\
\hline $\begin{array}{l}\text { Screening colonos- } \\
\text { copy }[n(\%)]\end{array}$ & $854(54.3)$ & $833(52.6)$ & 0.37 \\
\hline
\end{tabular}

Table 2 Neoplasia detection rates in Group 1 and Group 2.

\begin{tabular}{|llll}
\hline Detection rate & $\begin{array}{l}\text { Group 1 } \\
\mathbf{n = 1 5 7 3} \\
\mathbf{n}(\%)\end{array}$ & $\begin{array}{l}\text { Group 2 } \\
\mathbf{n = 1 5 8 3} \\
\mathbf{n}(\%)\end{array}$ & $\mathbf{P}$ \\
\hline $\begin{array}{l}\text { Overall patients with } \\
\text { neoplasias }\end{array}$ & $288(18.3)$ & $427(27.0)$ & $<0.0001$ \\
$\begin{array}{l}\text { Patients with } \\
\text { high-risk adenomas }\end{array}$ & $76(4.8)$ & $142(9.0)$ & $<0.0001$ \\
\hline $\begin{array}{l}\text { Patients with } \\
\text { carcinomas }\end{array}$ & $16(1.0)$ & $21(1.3)$ & 0.52 \\
\hline $\begin{array}{l}\text { Patients with } \\
\text { serrated adenomas }\end{array}$ & $11(0.7)$ & $14(0.9)$ & 0.70 \\
\hline $\begin{array}{l}\text { Patients with neo- } \\
\text { plasias in the right } \\
\text { colon }\end{array}$ & $112(7.1)$ & $154(9.7)$ & 0.01 \\
\hline $\begin{array}{l}\text { Patients with neo- } \\
\text { plasias in screening }\end{array}$ & $141 / 854(16.5)$ & $233 / 833(28.0)$ & $<0.0001$ \\
\hline
\end{tabular}

Regarding the time of the procedure, 255 of 916 cases in the early group $(27.8 \%)$ and 172 of 667 cases in the late group had neoplasias $(25.8 \%)(P=0.39$, OR $1.1[95 \% \mathrm{CI} 0.88-1.40])$.

Neoplasias were found in 191 of 618 internal patients (30.9\%) and in 236 of $965(24.5 \%)$ external patients $(P=0.006$, OR 1.38 [95\% CI 1.10-1.74]). The average BBPS was $6.8 \pm 1.5$ in internal patients and $6.2 \pm 1.6$ in external patients $(P<0.0001)$. Quality indicators in group 2 are summarized in $\bullet$ Table 3.

\section{Discussion}

Our study demonstrates that it is possible to improve the performance of colonoscopy in the everyday scenario of a non-academic private endoscopy center, with a higher neoplasia detection rate, by means of a quality program based on instructive measures to patients and endoscopists. To our knowledge, this is the first study that evaluated quantitative parameters and reached this conclusion.

The need for quality assurance in colonoscopy has been emphasized by several authors and by endoscopy organizations $[2,9$, 20]. There are multiple reasons for evaluating quality through accurate data, namely screening benefits, correct health funding, and legal issues $[9,21]$. Furthermore, quality assurance evaluations according to international standards are recommended for an adequate comparison among centers and endoscopists [9].

Our quality program allowed us to reach an optimal cecal intubation and to document this target according to recommendations in the literature $[2,5,7,9]$.

Detection and removal of adenomas reduces the risk of subsequent cancer [22]. A recent study by Corley et al showed the importance of detection of adenomas in reducing risks of interval colorectal cancer, advanced-stage interval cancer, and fatal inter- 


\begin{tabular}{|c|c|c|c|c|}
\hline Quality indicator & $\begin{array}{l}\text { Patients with } \\
\text { neoplasia }\end{array}$ & $\begin{array}{l}\text { Patients without } \\
\text { neoplasia }\end{array}$ & $\boldsymbol{P}$ & OR $(95 \% \mathrm{Cl})$ \\
\hline Mean BBPS & $6.65 \pm 1.5$ & $6.43 \pm 1.6$ & 0.017 & \\
\hline BBPS $\geq 6(n=1,174)$ & $333(28.4 \%)$ & 841 & 0.02 & $1.37(1.04-1.80)$ \\
\hline BBPS $<6(n=406)$ & $91(22.4 \%)$ & 315 & & \\
\hline Early group ( $n=916)$ & $255(27.8 \%)$ & 661 & 0.39 & $1.1(0.88-1.40)$ \\
\hline Late group $(n=667)$ & $172(25.8 \%)$ & 495 & & \\
\hline Patients from our center $(n=618)$ & $191(30.9 \%)$ & 427 & 0.006 & $1.38(1.10-1.74)$ \\
\hline Patients from other institutions $(n=965)$ & $236(24.5 \%)$ & 729 & & \\
\hline
\end{tabular}

Table 3 Quality indicators in Group 2.

BBPS, Boston bowel preparation scale.

val cancer [6]. Owing to these reasons, the neoplasia detection rate was considered the main outcome of our study. Our detection rates were similar to that reported by Barclay et al. [11], (overall detection rate $23.5 \%$ and advanced adenoma detection rate $5.2 \%$ ), but we want to point out the significant increase in the rates when the quality program was implemented. Therefore, it can be stated that quality measurement is another factor that influences the neoplasia detection rate. The improvement in neoplasia detection rate was also demonstrated when high-risk adenomas, neoplasias detected on screening colonoscopies, and neoplasias located in the right colon were considered. It is important to achieve a higher neoplasia detection rate in the right colon. Given the small number of serrated adenomas and cancerous lesions found in both groups, we were unable to identify betweengroup differences in rates of serrated adenoma or carcinoma detection.

Introduction of the instruction program allowed us to adequately evaluate additional quality indicators. An appropriate colon cleansing is one of the key factors in achieving a high-quality colonoscopy. Incomplete visualization of the mucosa leads to longer studies, higher complication rates, shorter intervals between colonoscopies, and increased costs [12]. Furthermore, with suboptimal preparation, the rate of missed adenomas rises to $42 \%$ for all adenomas and to $27 \%$ for advanced adenomas [13]. Multiple workgroups and international recommendations suggest that every colonoscopy report should include an evaluation of the quality of bowel preparation $[3,5,9,23]$. In our center, we chose the BBPS because it evaluates total visualization of the mucosa (after washing and removing debris) and because a good score is related to polyp detection rates $[16,24]$. According to these data, we could also demonstrate that the neoplasia detection rate improved in patients with an adequate preparation, either considering the mean value or a cutoff level of 6 .

Some authors have suggested that the time at which the procedure is performed might influence neoplasia detection rates. We failed to find any difference between early and late colonoscopies. On the other hand, results were significantly better when patients were from our center, probably because our attending physicians exhaustively explained the requirements for a good preparation.

We did not evaluate the colonoscopy withdrawal time because it was not recorded in the first period and after instructing the endoscopists, a 6-minute interval was systematically employed. Considering that, we realize that a weakness of our study lies in the lack of some quality data in group 1. Another weakness of our study is that no long-term efficacy was evaluated. A Hawthorne effect cannot be excluded and the possibility exists that the endoscopists improved their behavior in response to awareness of being observed but that is impossible to assess.
The main strength of our investigation is the quantitative comparison that demonstrated the benefits of a quality program. Another strong point is the homogeneity of both comparison groups, because the center where the procedures were performed, the social status of the patients, the team (endoscopists, anesthesiologists and nurses), and the equipment used (endoscopes of the standard series available in our country and endoscopy rooms) all were the same.

We conclude that implementation of a program to improve the quality of colonoscopy facilitates detection of a significantly higher number of neoplasias, including high-risk adenomas and right colon adenomas. We should also point out that patients who receive an oral and personalized explanation by an experienced gastroenterologist, in addition to written instructions, can achieve better compliance and better colon cleansing. Quality should be systematically measured and reported. Instruction programs focused on both patients and physicians should be implemented in private endoscopy centers that are looking to improve their performance.

\section{Competing interests: None}

\section{References}

1 Minoli G, Radaelli F. A new way for improving the quality of colonoscopy? Dig Liver Dis 2010; 42: 285-286

2 Lee TJW, Rutter MD, Blanks RG et al. Colonoscopy quality measures: experience from the NHS Bowel Cancer Screening Programme. Gut 2012; 61: $1050-1057$

3 Lieberman D, Nadel M, Smith RA et al. Standardized colonoscopy reporting and data system: report of the Quality Assurance Task Group of the National Colorectal Cancer Roundtable. Gastrointest Endosc 2007; 65: 757-766

4 Kaminski MF, Regula J, Kraszewska E et al. Quality indicators for colonoscopy and the risk of interval cancer. N Engl J Med 2010; 362: $1795-1803$

5 Rex DK, Petrini JL, Baron TH et al. Quality indicators for colonoscopy. Gastrointest Endosc 2006; 63: S16-S28

6 Corley DA, Jensen $C D$, Marks AR et al. Adenoma detection rate and risk of colorectal cancer and death. N Engl J Med 2014; 370: 1298-1306

7 Rex DK, Bond JH, Winawer S et al. Quality in the technical performance of colonoscopy and the continuous quality improvement process for colonoscopy: recommendations of the U. S. Multi-Society Task Force on colorectal cancer. Am J Gastroenterol 2002; 97: 1296-1308

8 Lieberman DA, Rex DK, Winawer SJ et al. Guidelines for colonoscopy surveillance after screening and polypectomy: a consensus update by the U. S. Multi-Society Task Force on Colorectal Cancer. Gastroenterology 2012; 143: 844-857

9 Rembacken B, Hassan C, Riemann JF et al. Quality in screening colonoscopy: position statement of the European Society of Gastrointestinal Endoscopy (ESGE). Endoscopy 2012; 44: 957 - 968

10 Lieberman D. A call to action - Measuring the quality of colonoscopy. $\mathrm{N}$ Engl J Med 2006; 355: 2588 - 2589

11 Barclay RL, Vicari JJ, Doughty AS et al. Colonoscopic withdrawal times and adenoma detection during screening colonoscopy. N Engl J Med 2006; 355: $2533-2541$ 
12 Hendry PO, Jenkins JT, Diament RH. The impact of poor bowel preparation on colonoscopy: a prospective single center study of 10,571 colonoscopies. Colorectal Dis 2007; 9: 745-748

13 Lebwohl B, Kastrinos F, Glick M et al. The impact of suboptimal bowel preparation on adenoma miss rates and the factors associated with early repeat colonoscopy. Gastrointest Endosc 2011; 73: 1207-1214

14 Cohen LB. Split dosing of bowel preparations for colonoscopy: an analysis of its efficacy,safety and tolerability. Gastrointest Endosc 2010; 72: 406-412

15 Parra-Blanco A, Nicolás-Pérez D, Gimeno-García A et al. The timing of bowel preparation before colonoscopy determines the quality of cleansing, and is a significant factor contributing to the detection of flat lesions: a randomized study. World J Gastroenterol 2006; 12: 6161-6166

16 Lai EJ, Calderwood AH, Doros G et al. The Boston bowel preparation scale: a valid and reliable instrument for colonoscopy-oriented research. Gastrointest Endosc 2009; 69: 620-625

17 Connor A, Tolan D, Hughes $S$ et al. Consensus guidelines for the safe prescription and administration of oral bowel-cleansing agents. Gut 2012; 61: $1525-1532$
18 Atkin WS, Morson BC, Cuzick J. Long-term risk of colorectal cancer after excision of rectosigmoid adenomas. N Eng J Med 1992; 326: 658 -662

19 IJspeert JEG, Vermeulen L, Meijer GA et al. Serrated neoplasia-role in colorectal carcinogenesis and clinical implications. Nat Rev Gastroenterol Hepatol 2015; 12: 401 -409

20 Imperiali G, Minoli G, Meucci GM et al. Effectiveness of a continuous quality improvement program on colonoscopy practice. Endoscopy 2007; 39: $314-318$

21 Rex $D$. Avoiding and defending malpractice suits for postcolonoscopy cancer:advice from an expert witness. Clin Gastroenterol Hepatol 2013; $11: 768-773$

22 Winawer SJ, Zauber AG, Ho MN et al. Prevention of colorectal cancer by colonoscopic polypectomy. The National Polyp Study Workgroup. N Engl J Med 1993; 329: 1977 -1981

23 Jover $R$, Herráiz M, Alarcón 0 et al. Clinical practice guidelines: quality of colonoscopy in colorectal cancer screening. Endoscopy 2012; 44: $444-451$

24 Calderwood $A H$, Jacobson BC. Comprehensive validation of the Boston bowel preparation scale. Gastrointest Endosc 2010; 72: 686-692 